\title{
Research on Carbon Emission Reduction and Pricing in Dual-Channel Supply Chain with Fairness Concerns
}

\author{
Lin Deng \\ School of Economics and Management \\ Guangxi University of Science and Technology \\ Liuzhou, China \\ 335473726@qq.com
}

\author{
Zhigao Liao* \\ Department Of Postgraduate Administration \\ Guangxi University of Science and Technology \\ Liuzhou, China \\ 46154910@qq.com
}

\author{
Xueying Cao \\ School of Economics and Management \\ Guangxi University of Science and Technology \\ Liuzhou, China
}

\begin{abstract}
Under the constraint of carbon emission reduction, this paper analyzes the impact of the fairness concern coefficient on the strategies of members in the dual-channel supply chain. This paper discusses two decision scenarios, the benchmark model without the fairness concern and the model with the retailers' fairness concern. The results show that when retailers focus on fairness, retailers' profits will increase, but manufacturers will suffer losses. However, retailers don't always benefit from fairness concerns. When the investment cost coefficient of emission reduction is low, if the fairness concern coefficient exceeds a threshold, retailers' profits will decrease as the coefficient of fairness increases. And as the proportion of consumers who prefer traditional channels increases, manufacturers' profits will first decrease then increase, but retailers' profits will keep increasing.
\end{abstract}

Keywords-carbon emission reduction; fairness concerns; dual-channel supply chain; carbon trading policy

\section{INTRODUCTION}

The frequent occurrence of extreme weather phenomena in recent years has received high attention from the international community. Increasing greenhouse gas concentrations will trigger larger global heat waves and extreme weather. In order to cope with the increasingly serious environmental problems, countries have formulated policies to control carbon emissions, such as carbon trading policy, carbon tax policy, government subsidy policy. At present, the implementation of carbon trading policy is the largest and most widely used. China has launched pilot projects on carbon emissions trading in seven provinces and cities across the country. Since 2010, Tesla has generated nearly $\$ 2$ billion in revenue by selling carbon credits.

Many scholars have studied the production, emission reduction and pricing decisions of the supply chain under the carbon policy from the perspective of the supply chain. Xi et al.

This work is supported by the projects of Guangxi Philosophy and Social Science Project (17FJY007), Innovation Project of Guangxi Graduate

Education (YCSZ2014203) and National Social Science Fund Western Project (Project No. 19XGL025)
[1] introduced carbon regulation measures such as carbon allowance, carbon tax, cap-and-trade regulation into the classic economic order batch model, and compared the optimal order quantity and the lowest total cost before and after the introduction of carbon regulation measures. Bai et al. [2] considered emission reduction investment and promotion efforts under the supervision of quotas and transactions. They proposed two contracts to coordinate supply chains.

The research on the single-channel low-carbon supply chain has been very rich. With the rapid development of ecommerce, many manufacturers have established online direct sales channels, such as Gree and Haier. They have both retail stores and online sales platforms. Therefore, many scholars began to study the dual-channel low-carbon supply chain. Ji et al. [3] considered the carbon trading policy and studied the decision-making issues of the supply chain members in the four situations of whether the manufacturer opened the direct sales channel and whether the retailer participated in the low-carbon promotion. $\mathrm{Xu}$ [4] studied the impact of total carbon emission control on the pricing of dual-channel supply chains and the coordination conditions of channel price discount contracts. Liu et al. [5] found that when manufacturers open online direct sales channels and share revenue with retailers, there is a range of revenue sharing ratios that can optimize carbon emission reduction levels and supply chain members' profits.

The above research is based on the premise of "rational economic man", assuming that channel members only focus on maximizing their own interests. But policy makers often show great concern about fairness, that is, decision-makers not only focus on their own profits, but also on the profits of other members. For example, due to the unilateral increase in wholesale prices by Master Kong, Guangzhou Friendship Group felt unfairly treated. The cooperation between the two sides broke down. So in the supply chain, the fair concerns of members are also a new factor to be considered. Fehr and Schmidt [6] introduced the problem of distributional equity 
In order to produce low-carbon products, manufacturers into the supply chain model. Du and Nie [7] studied a quantity discount contract in a two-tier supply chain consisting of one supplier and two retailers. They considered peers to induce fair concerns and assign fairness concerns. However, none of the above references consider manufacturers producing low-carbon products in the supply chain. Few literature studies consider the supply chain emission reduction and pricing issues of member fairness in dual channels.

Therefore, this paper studies a dual-channel low-carbon supply chain consisting of one manufacturer and one retailer under two different decision-making modes where the retailer is not concerned about fairness and the retailer is concerned about fairness. This paper focuses on the impact of retailers' fairness concerns and consumer channel preferences on carbon emission reductions, pricing decisions and profitability of supply chain members.

\section{PROBlem AsSumptions AND MODEL DESCRIPTION}

Under the influence of cap-and-trade regulation, manufacturers use technological transformation to reduce carbon emissions from products and provide low-carbon products to the market. Consumers can choose traditional retail channels to purchase low-carbon products at retailers according to their own preferences, or purchase low-carbon products through online direct sales channels provided by manufacturers.

Similar to Ji [3], this paper assumes that the demand for retail channels and direct sales channels is linear with retail prices, direct selling prices, and carbon emission reduction levels. So the two-channel demand function is as follows:

$$
\begin{aligned}
& D_{\mathrm{r}}=\theta a-b_{1} p_{r}+b_{2} p_{m} \\
& D_{\mathrm{m}}=(1-\theta) a-b_{1} p_{m}+b_{2} p_{r}
\end{aligned}
$$

Among them, $D_{\mathrm{r}}, D_{\mathrm{m}}$ are the demand for retail channels and direct sales channels. Demand is positively correlated with the price of the respective channel and negatively correlated with the price of the competitive channel; $a$ is the potential market demand for low-carbon products; $\theta$ represents the proportion of consumers who prefer traditional retail channels, and $1-\theta$ is the proportion of consumers who prefer to buy lowcarbon products from direct sales channels; $p_{r}, p_{m}$ are the sales prices of retail channels and direct sales channels respectively; $b_{1}$ represents the price sensitivity coefficient, and $b_{2}$ represents the cross-price sensitivity coefficient, apparently $b_{1}>b_{2}$.In addition, the manufacturer's wholesale price to the retailer is $W$.

In the carbon trading market, the government allocates free carbon emissions $A$ to manufacturers $(A>0)$. When the manufacturer's carbon emissions exceed the limit $A$, the manufacturer needs to purchase carbon credits in the carbon market. Conversely, when manufacturers reduce their carbon emissions through technological transformations so that carbon emissions are less than limit A, manufacturers can sell the remaining carbon credits on the carbon market. In the carbon market, the trading price of carbon is $p_{e}$. must invest in carbon reduction technologies. Similar to Ji [3], this paper assumes that the investment cost of carbon emission reduction is: $C(e)=\frac{1}{2} k e^{2}$.Among them, $k$ is the investment cost coefficient of emission reduction, and e is the carbon emission reduction amount per unit product. In addition, it is assumed that $c$ is the unit product cost when no investment in emission reduction is made, and $e_{0}$ is the initial unit product carbon emission.

Based on the above assumptions, the manufacturer's profit and the retailer's profit are:

$$
\begin{aligned}
& \pi_{m}=(w-c) D_{r}+\left(p_{m}-c\right) D_{m}-\frac{1}{2} k e^{2}-p_{e}\left[\left(D_{m}+D_{r}\right)\left(e_{0}-e\right)-A\right] \\
& \pi_{r}=\left(p_{r}-w\right) D_{r}
\end{aligned}
$$

In order to ensure that the demand for each channel and the profit of the members of the supply chain are positive, the constraints need to be met:

$$
\left(b_{1}-b_{2}\right)\left[p_{e}\left(2 k e_{0}-a p_{e}\right)+2 c k\right]+2 a \theta\left[p_{e}^{2}\left(b_{1}-b_{2}\right)-k\right]<0
$$

\section{MODEL BUILDING}

\section{A. Benchmark Model}

Manufacturers and retailers aim to maximize their profits when retailers are not concerned about fairness. As the leader of the Stackelberg game, manufacturers first determine the optimal carbon emission reduction, the wholesale price and direct selling price of the product. As a follower, the retailer determines the selling price of the product based on the manufacturer's wholesale price and direct selling price. According to the inverse solution method, the optimal decision of the supply chain members can be obtained.

Theorem 1 In the case of the retailer not paying attention to fairness, the manufacturer's optimal emission reduction level, optimal wholesale price, optimal direct sales and retailer's optimal retail price are as follows:

$$
\begin{aligned}
& e_{A}^{*}=\left[p_{e}\left[a\left[b_{1}(\theta-2)-b_{2} \theta\right]+\left(b_{1}-b_{2}\right)\left(3 b_{1}+b_{2}\right)\left(c+e_{0} p_{e}\right)\right]\right] / T_{1} \\
& a\left[\begin{array}{l}
2 b_{1}^{3} p_{e}^{2}(\theta+1)+b_{1}^{2}\left[b_{2} p_{e}^{2}(3-4 \theta)-4 k \theta\right]+2 b_{1} b_{2} \\
{\left[b_{2} p_{e}^{2}(\theta-2)+2 k(\theta-1)\right]-b_{2}^{3} p_{e}^{2}}
\end{array}\right] \\
& w_{A}^{*}=\frac{-2 b_{1}\left[2 k\left(b_{1}-b_{2}\right)\left(b_{1}+b_{2}\right)\left(c+e_{0} p_{e}\right)\right]}{2\left(b_{1}-b_{2}\right)\left(b_{1}+b_{2}\right) T_{1}} \\
& {\left[-2 \mathrm{a} \theta\left(b_{1}-b_{2}\right)\right]\left[p_{e}^{2}\left(b_{1}-b_{2}\right)\left(2 b_{1}+b_{2}\right)-2 b_{1} k\right]+} \\
& a b_{1}\left[p_{e}^{2}\left(b_{1}-b_{2}\right)\left(5 b_{1}+3 b_{2}\right)-4 b_{1} k\right] \\
& p_{m A}^{*}=\frac{-2 b_{1}\left[2 k\left(b_{1}-b_{2}\right)\left(b_{1}+b_{2}\right)\left(c+e_{0} p_{e}\right)\right]}{2\left(b_{1}-b_{2}\right)\left(b_{1}+b_{2}\right) T_{1}} \\
& a\left[\begin{array}{l}
b_{1}^{3} p_{e}^{2}(4 \theta+1)+b_{1}^{2}\left[4 b_{2} p_{e}^{2}-6 \theta\left(b_{2} p_{e}^{2}+k\right)\right]+b_{1} b_{2} \\
{\left[4 k(\theta-1)-3 b_{2} p_{e}^{2}\right]+2 b_{2}^{2}\left[b_{2} p_{e}^{2}(\theta-1)+k \theta\right]}
\end{array}\right] \\
& p_{r A}^{*}=\frac{-\left(b_{1}+b_{2}\right)\left[2 k\left(b_{1}-b_{2}\right)\left(b_{1}+b_{2}\right)\left(c+e_{0} p_{e}\right)\right]}{2\left(b_{1}-b_{2}\right)\left(b_{1}+b_{2}\right) T_{1}}
\end{aligned}
$$




\section{RESUlts AND Discussions}

$$
T_{1}=p_{e}^{2}\left(b_{1}-b_{2}\right)\left(3 b_{1}+b_{2}\right)-4 b_{1} k
$$

In order for the model to be established, the constraints need to be met: $T_{1}<0$.

\section{B. Fairness Concerns}

In the context of carbon reduction, manufacturers act as control companies, which are the leaders of the supply chain, and retailers are followers. And in the dual-channel sales model, the contradiction between manufacturers and retailers has intensified. Retailer's profits will be eroded by the opening of direct sales channels. Therefore, the retailer's fairness concern is more obvious. Retailers are not only concerned about their own profits, but also about the gap with manufacturers' profits. Retailers aim to maximize utility. Similar to Du [7], this paper introduces the fairness concern coefficient $\lambda$ to describe the utility of retailers. The retailer's utility function is as follows:

$$
U_{r}=\pi_{r}-\lambda\left(\pi_{m}-\pi_{r}\right), 0 \leq \lambda \leq 1
$$

Theorem 2 In the case of the retailer paying attention to fairness, the manufacturer's optimal emission reduction level, optimal wholesale price, optimal direct sales and retailer's optimal retail price are as follows:

$$
\begin{aligned}
& e_{B}^{*}=\left[p_{e}\left[\begin{array}{l}
a\left[b_{1}(3 \lambda \theta+\theta-4 \lambda-2)-b_{2} \theta(3 \lambda+1)\right]+ \\
\left(b_{1}-b_{2}\right)\left[b_{1}(5 \lambda+3)+3 b_{2} \lambda+b_{2}\right]\left(c+e_{0} p_{e}\right)
\end{array}\right]\right] / T_{2} \\
& a\left[\begin{array}{l}
2 b_{1}^{3} p_{e}^{2}[\theta(1-\lambda)+3 \lambda+1]+b_{1}^{2}\left[b_{2} p_{e}^{2}(3 \lambda-4 \theta+3)-4 k \theta(\lambda+1)\right] \\
+2 b_{1} b_{2}\left[b_{2} p_{e}^{2}(3 \lambda \theta+\theta-4 \lambda-2)+2 k(\theta-1)(2 \lambda+1)\right] \\
-b_{2}^{2}\left[b_{2} p_{e}^{2}(4 \theta \lambda+\lambda+1)+4 k \theta \lambda\right]
\end{array}\right] \\
& w_{B}^{*}=\frac{-4 k\left(b_{1}-b_{2}\right)\left(b_{1}+b_{2}\right)\left(c+e_{0} p_{e}\right)\left(3 b_{1} \lambda+b_{1}-b_{2} \lambda\right)}{2\left(b_{1}-b_{2}\right)\left(b_{1}+b_{2}\right) T_{2}} \\
& -\left[\begin{array}{l}
{\left[\begin{array}{l}
b_{1}^{3} p_{e}^{2}[\theta(8 \lambda+4)-9 \lambda-5] \\
+2 b_{1}^{2}\left[b_{2} p_{e}^{2}(-5 \theta \lambda-3 \theta+\lambda+1)-2 k(\theta-1)(2 \lambda+1)\right] \\
-b_{1} b_{2}\left[b_{2} p_{e}^{2}(-4 \theta \lambda+7 \lambda+3)+4 k \theta(2 \lambda+1)\right] \\
+2 b_{2}^{3} p_{e}^{2} \theta(3 \lambda+1)
\end{array}\right]} \\
+4 b_{1} k(2 \lambda+1)\left(b_{1}-b_{2}\right)\left(b_{1}+b_{2}\right)\left(c+e_{0} p_{e}\right)
\end{array}\right] \\
& a\left[\begin{array}{l}
b_{1}^{3} p_{e}^{2}[\theta(6 \lambda+4)+2 \theta+1]-b_{1}^{2}\left[\begin{array}{l}
b_{2} p_{e}^{2}(8 \theta \lambda+6 \theta-7 \lambda-4) \\
+6 k \theta(2 \lambda+1)
\end{array}\right] \\
-b_{1} b_{2}\left[b_{2} p_{e}^{2}(2(\theta+2) \lambda+3)-4 k(\theta-1)(2 \lambda+1)\right]+ \\
b_{2}^{2}\left[b_{2} p_{e}^{2}(4 \theta \lambda+2 \theta-5 \lambda-2)+2 k \theta(2 \lambda+1)\right]
\end{array}\right] \\
& p_{r B}^{*}=\frac{-2 k(2 \lambda+1)\left(b_{1}-b_{2}\right)\left(b_{1}+b_{2}\right)^{2}\left(c+e_{0} p_{e}\right)}{2\left(b_{1}-b_{2}\right)\left(b_{1}+b_{2}\right) T_{2}} \\
& T_{2}=b_{1}^{2} p_{e}^{2}(5 \lambda+3)-2 b_{1}\left[b_{2} p_{e}^{2}(\lambda+1)+k(4 \lambda+2)\right]-b_{2}^{2} p_{e}^{2}(3 \lambda+1)
\end{aligned}
$$

In order for the model to be established, the constraints need to be met: $T_{2}<0$.
Proposition 1 (1) $\frac{\partial e_{B}^{*}}{\partial \lambda}<0, \frac{\partial p_{m B}^{*}}{\partial \lambda}>0, \frac{\partial p_{r B}^{*}}{\partial \lambda}>0, \frac{\partial \pi_{m B}^{*}}{\partial \lambda}>0$;

(2) If $\frac{3 b_{1}^{2} p_{e}^{2}-2 b_{1} b_{2} p_{e}^{2}-b_{2}^{2} p_{e}^{2}}{4 b_{1}}<k<\frac{4 b_{1}^{2} p_{e}^{2}-3 b_{1} b_{2} p_{e}^{2}-b_{2}^{2} p_{e}^{2}}{4 b_{1}}$, th en $\frac{\partial w_{B}^{*}}{\partial \lambda}>0$; if $k>\frac{4 b_{1}^{2} p_{e}^{2}-3 b_{1} b_{2} p_{e}^{2}-b_{2}^{2} p_{e}^{2}}{4 b_{1}}$, then $\frac{\partial w_{B}^{*}}{\partial \lambda}<0$;

(3) When $p_{e}^{2}\left(b_{1}-b_{2}\right)<k<\frac{13 b_{1}^{2} p_{e}^{2}-14 b_{1} b_{2} p_{e}^{2}+b_{2}^{2} p_{e}^{2}}{12 b_{1}}$,

if $0<\lambda<\frac{-4 b_{1}^{2} p_{e}^{2}+4 b_{1} b_{2} p_{e}^{2}+4 b_{1} k}{9 b_{1}^{2} p_{e}^{2}-10 b_{1} b_{2} p_{e}^{2}-8 b_{1} k+b_{2}^{2} p_{e}^{2}}$, then $\frac{\partial \pi_{r B}^{*}}{\partial \lambda}>0$;

if $\lambda>\frac{-4 b_{1}^{2} p_{e}^{2}+4 b_{1} b_{2} p_{e}^{2}+4 b_{1} k}{9 b_{1}^{2} p_{e}^{2}-10 b_{1} b_{2} p_{e}^{2}-8 b_{1} k+b_{2}^{2} p_{e}^{2}}$, then $\frac{\partial \pi_{r B}^{*}}{\partial \lambda}<0$; if

$k>\frac{13 b_{1}^{2} p_{e}^{2}-14 b_{1} b_{2} p_{e}^{2}+b_{2}^{2} p_{e}^{2}}{12 b_{1}}$, then $\frac{\partial \pi_{r B}^{*}}{\partial \lambda}>0$.

Proposition 1 shows that when retailers focus on fairness, carbon emissions decrease as the fairness concern coefficient $\lambda$ increases. Both the manufacturer's direct selling price and the retailer's retail price increase as $\lambda$ increases. The impact of $\lambda$ on the manufacturer's wholesale price and retailer's profit is determined by the size of the investment cost coefficient $\mathrm{k}$. When $\mathrm{k}$ is high, the wholesale price decreases with the increase of $\lambda$, and the retailer's profit increases with the increase of $\lambda$. But when $\mathrm{k}$ is low, the wholesale price increases as $\lambda$ increases, and at this point, retailers do not always benefit from fairness concerns. When $\lambda$ exceeds a threshold, the retailer's profit decreases as $\lambda$ increases. And the profit of the manufacturer is always lost because of the fairness concerns of the retailer.

Proposition 2 (1) $\frac{\partial e_{A}^{*}}{\partial \theta}<0, \frac{\partial w_{A}^{*}}{\partial \theta}>0, \frac{\partial p_{r A}^{*}}{\partial \theta}>0, \frac{\partial \pi_{r A}^{*}}{\partial \theta}>0$;

(2) If $k>\frac{2 b_{1}^{2} p_{e}^{2}-b_{1} b_{2} p_{e}^{2}-b_{2}^{2} p_{e}^{2}}{2 b_{1}}$, then $\frac{\partial p_{m A}^{*}}{\partial \theta}<0$; if

$\frac{3 b_{1}^{2} p_{e}^{2}-2 b_{1} b_{2} p_{e}^{2}-b_{2}^{2} p_{e}^{2}}{4 b_{1}}<k<\frac{2 b_{1}^{2} p_{e}^{2}-b_{1} b_{2} p_{e}^{2}-b_{2}^{2} p_{e}^{2}}{2 b_{1}}, \mathrm{t}$ hen $\frac{\partial p_{m A}^{*}}{\partial \theta}>0$;

$$
\begin{gathered}
a b_{1}^{2} p_{e}^{2}-a b_{1} b_{2} p_{e}^{2}-2 a b_{1} k+ \\
\text { (3)If } 0<\theta<\frac{b_{1}^{2} c k+b_{1}^{2} k e_{0} p_{e}-b_{2}^{2} c k-b_{2}^{2} k e_{0} p_{e}}{2 a b_{1}^{2} p_{e}^{2}-2 a b_{1} b_{2} p_{e}^{2}-3 a b_{1} k+a b_{2} k} \text {, then } \frac{\partial \pi_{m A}^{*}}{\partial \theta}<0 \text {; } \\
\text { if } \frac{b_{1}^{2} c k+b_{1}^{2} k e_{0} p_{e}-b_{2}^{2} c k-b_{2}^{2} k e_{0} p_{e}}{2 a b_{1}^{2} p_{e}^{2}-2 a b_{1} b_{2} p_{e}^{2}-3 a b_{1} k+a b_{2} k}<\theta<1
\end{gathered}
$$

Proposition 2 shows that wholesale prices, retail prices, and retailer profits increase as the proportion of consumers 
preferring traditional retail channels $\theta$ increases, as the retailer is not concerned about fairness. However, carbon emission reductions decrease as $\theta$ increases. When $\mathrm{k}$ is very high, the direct selling price decreases as $\theta$ increases, but when $\mathrm{k}$ is low, the direct selling price increases as $\theta$ increases. When $\theta$ is low, the manufacturer's profit decreases as $\theta$ increases; when $\theta$ is high, the manufacturer's profit increases as $\theta$ increases.

Proposition 3 (1) $\frac{\partial e_{B}^{*}}{\partial \theta}<0, \frac{\partial w_{B}^{*}}{\partial \theta}>0, \frac{\partial p_{r B}^{*}}{\partial \theta}>0, \frac{\partial \pi_{r B}^{*}}{\partial \theta}>0$;

(2) If $k>k_{1}$, then $\frac{\partial p_{m B}^{*}}{\partial \theta}<0$;if $k_{2}<k<k_{1}$, then $\frac{\partial p_{m B}^{*}}{\partial \theta}>0$, where

$k_{1}=\left(4 b_{1}^{2} p_{e}^{2} \lambda+2 b_{1}^{2} p_{e}^{2}-b_{1} b_{2} p_{e}^{2} \lambda-3 b_{2}^{2} p_{e}^{2} \lambda-b_{2}^{2} p_{e}^{2}\right) /\left(4 b_{1} \lambda+2 b_{1}\right)$,

$k_{2}=\left(5 b_{1}^{2} p_{e}^{2} \lambda+3 b_{1}^{2} p_{e}^{2}-2 b_{1} b_{2} p_{e}^{2} \lambda-3 b_{2}^{2} p_{e}^{2} \lambda-b_{2}^{2} p_{e}^{2}\right) /\left(8 b_{1} \lambda+4 b_{1}\right)$

$$
a b_{1}\left[(\lambda+1) p_{e}^{2}\left(b_{1}-b_{2}\right)-2 k(2 \lambda+1)\right]
$$

(3)If $0<\theta<\frac{+k(3 \lambda+1)\left(b_{1}-b_{2}\right)\left(b_{1}+b_{2}\right)\left(c+e_{0} p_{e}\right)}{a k\left[-b_{1}(5 \lambda+3)+3 b_{2} \lambda+b_{2}\right]+2 a b_{1}(\lambda+1) p_{e}^{2}\left(b_{1}-b_{2}\right)}$

, then $\frac{\partial \pi_{m B}^{*}}{\partial \theta}<0$;

if $\frac{a b_{1}\left[(\lambda+1) p_{e}^{2}\left(b_{1}-b_{2}\right)-2 k(2 \lambda+1)\right]}{a k\left[-b_{1}(5 \lambda+3)+3 b_{2} \lambda+b_{2}\right]+2 a b_{1}(\lambda+1) p_{e}^{2}\left(b_{1}-b_{2}\right)}<\theta<1$, then $\frac{\partial \pi_{m B}^{*}}{\partial \theta}>0$.

Proposition 3 shows that in the case of retailers paying attention to fairness, the trend of carbon emission reduction, wholesale price, retail price, direct selling price, manufacturer's profit and retailer's profit with consumer channel preference is consistent with Proposition 2.

\section{NUMERICAL EXAMPLES}

Values are used to discuss the impact of the fairness concern coefficient on the carbon emission reduction levels, the product prices and the profitability of supply chain members.

Let $a=685, b_{1}=1, b_{2}=0.3, e_{0}=15, c=118, p_{e}=20, A=6, \theta=0.4$

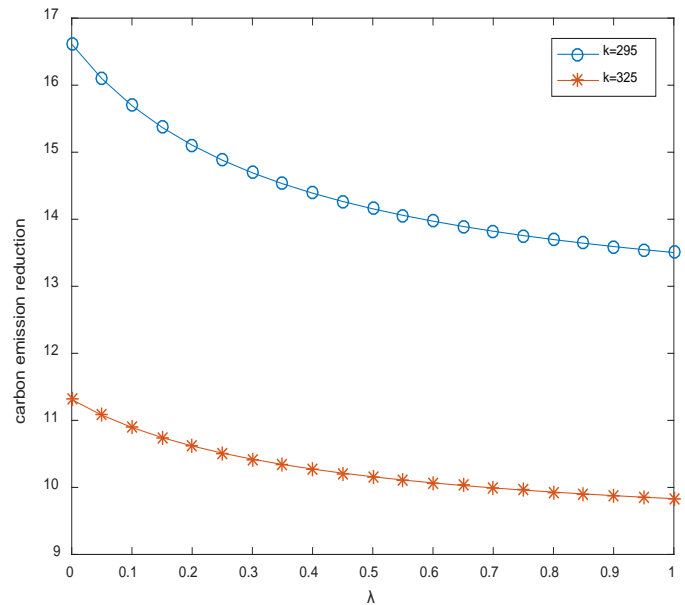

Fig. 1. Effect of $\lambda$ on the carbon emission reduction level

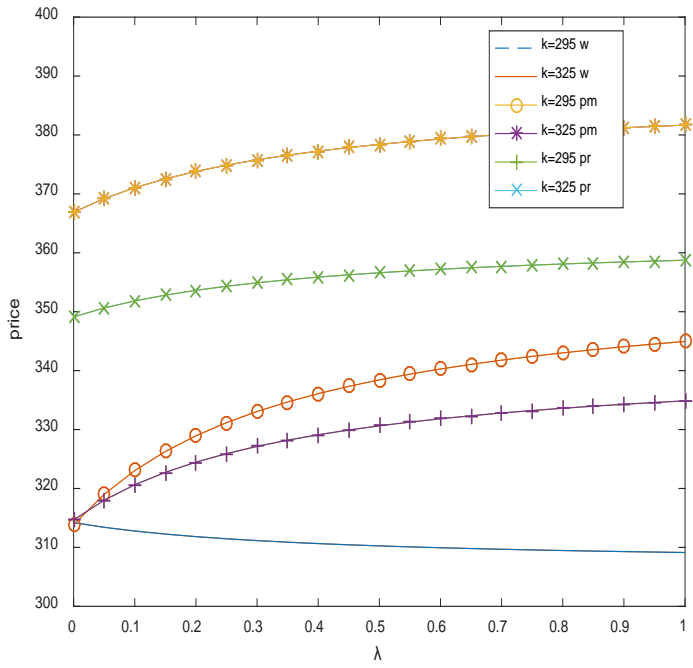

Fig. 2. Effect of $\lambda$ on the price

As can be seen from Fig.1, the carbon emission reduction of the product decreases as the coefficient of fairness increases. Therefore, retailers' fairness concerns are not conducive to carbon emission reduction activities. When the carbon emission reduction investment cost coefficient is high, the product has less carbon emission reduction. This is because of the higher the cost of carbon reduction, the weaker the ability and willingness of manufacturers to reduce carbon emissions.

Fig.2 shows that the wholesale price of products with the change of the fairness concern coefficient is affected by the cost coefficient of carbon emission reduction investment. When the carbon emission reduction investment cost coefficient is high, the wholesale price decreases with the increase of the fairness concern coefficient. When the carbon emission reduction investment cost coefficient is low, the wholesale price increases with the increase of the fairness concern factor. This is because when the manufacturer's emission reduction investment costs are high, the manufacturer's profit margin is relatively low. Manufacturers prevent retailers from continuing to focus on fairness by lowering wholesale prices. The fairness of the retailer brings more damage to the manufacturer than the manufacturer reduces the wholesale price. When the investment cost of emission reduction is low, the profit margin of the manufacturer is high. Manufacturers reduce losses from fairness concerns by increasing wholesale prices.

It can also be seen from Fig. 2 that both the direct selling price and the retail price of the product increase with the increase of the fairness concern factor. And the trends are similar. This is because when retailers start to pay attention to fairness, manufacturers compensate for the reduction in profits due to fairness concerns by raising direct selling prices. But retailers have also raised the retail price of their products because of their concern for fairness. The higher the cost of investment in emission reduction, the higher the wholesale price, direct selling price and retail price of the product. 


\section{CONCLUSIONS}

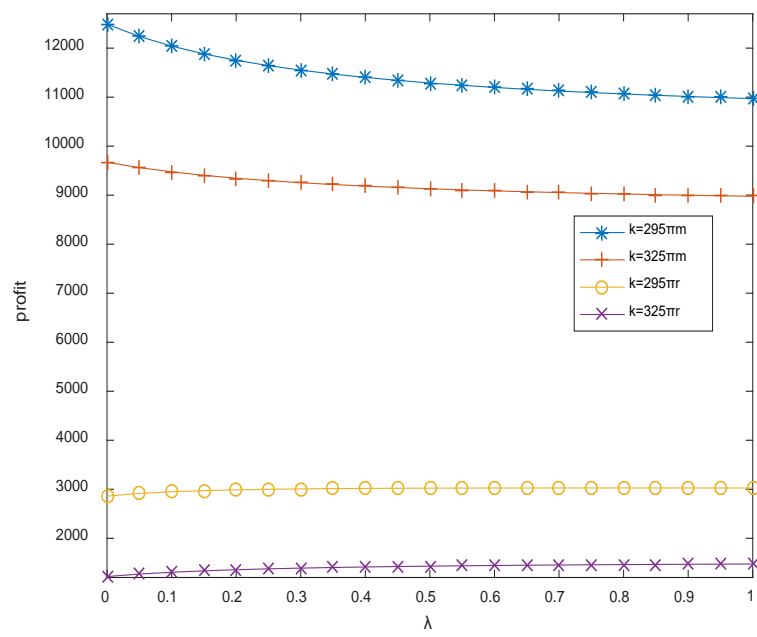

Fig. 3. Effect of $\lambda$ on members' profit

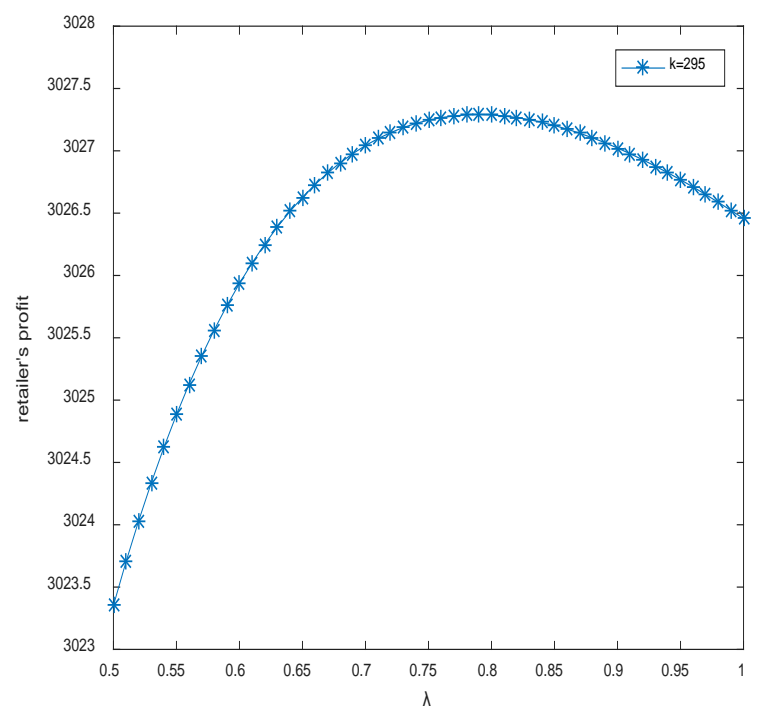

Fig. 4. Effect of $\lambda$ on the retailer's profit when $\mathrm{k}=295$

As can be seen from Figures 3-4, the manufacturer's profit has been reduced as the retailer's fairness factor has increased. And the lower the cost of investment in reducing emissions, the higher the profit of the manufacturer. But at this time, the profit of the manufacturer is affected by the coefficient of fairness. When $\mathrm{k}=325$, retailers' profits increase as the coefficient of fairness increases, and retailers always benefit from fairness concerns. When $\mathrm{k}=295$, if $0<\lambda<0.7895$, the retailer's profit increases with the increase of the fairness concern coefficient, but if $0.7895<\lambda<1$, the retailer's profit decreases with the increase of the fairness concern coefficient. Therefore, when the investment cost of emission reduction is low, retailers cannot pay too much attention to fairness. When the investment cost of emission reduction is high, retailers should pay attention to fairness.
This paper considers a dual-channel low-carbon supply chain consisting of one manufacturer and one retailer. The manufacturer carries out carbon emission reduction activities through a technological transformation under the cap and trade policy, and opens online direct sales channels in the environment of the rapid development of e-commerce. The article analyzes the dual-channel low-carbon supply chain under the two different decision-making modes of fairness neutrality of the retailer and fair concerns of the retailer, and draws the following conclusions:

(1)When the retailer focuses on fairness, carbon emissions decrease as the coefficient of fairness increases. Fairness concerns are not conducive to carbon emission reduction activities. As the coefficient of fairness increases, both the direct selling price of the manufacturer and the retail price of the retailer increase. When the cost of the investment in reducing emissions is high, the wholesale price of the manufacturer decreases with the increase of the fairness concern factor; when the investment cost factor is low, the wholesale price increases as the coefficient of fairness increases.

(2) The impact of the fairness concern coefficient on the retailer's profit is also determined by the size of the emission reduction investment cost coefficient. When the emission reduction investment cost coefficient is high, the retailer's profit increases with the increase of the fairness concern coefficient. But when the emission reduction investment cost coefficient is low, the retailer does not always benefit from fairness concerns. When the fairness concern coefficient exceeds a threshold, the retailer's profit decreases as the fairness concern coefficient increases. And the profit of the manufacturer is always lost because of the fairness concerns of the retailer.

(3)The more consumers prefer online direct sales channels, the greater the carbon reductions of products. The wholesale price of the product, the retail price of the product, and the profit of the retailer all increase with the proportion of consumers who prefer the traditional retail channel. With the increase in the proportion of consumers who have a preference for direct sales channels, when the investment coefficient of emission reduction is very high, the direct selling price will increase, but when the investment coefficient of emission reduction is low, the direct selling price will decrease.

(4)When the proportion of consumers preferring traditional retail channels is low, the profit of the manufacturer decreases with the proportion of consumers who prefer traditional retail channels. When the proportion of consumers who prefer traditional retail channels is high, the profit of the manufacturer increases with the proportion of consumers who prefer traditional retail channels. The retailer's profit has been increasing with the increase in the proportion of consumers who prefer traditional retail channels. Therefore, the manufacturer should take measures to make the channel preference of consumers have greater differences. The Retailer has to work hard to make consumers prefer to buy low-carbon products from retail channels. 


\section{REFERENCES}

[1] Xi C, Benjaafar S, Elomri A. The carbon-constrained EOQ [J]. Operations Research Letters, 2013, 41(2):172-179.

[2] Bai Q, Chen M, Lei X. Revenue and promotional cost-sharing contract versus two-part tariff contract in coordinating sustainable supply chain systems with deteriorating items [J].

International Journal of Production Economics, 2017, 187:85-101.

[3] Ji J, Zhang Z, Lei Y. Carbon emission reduction decisions in the retail/dual-channel supply chain with consumers' preference [J]. Journal of Cleaner Production, 2017, 141:852-867.
[4] Xu J, Qi Q, Bai Q. Coordinating a dual-channel supply chain with price discount contracts under carbon emission capacity regulation[J]. Applied Mathematical Modeling, 2018, 56:449-468.

[5] Liu M W, Xu Y S, Fu H, Low carbon supply chain decision-making and channel cooperation under dual channel background[J]Soft Science,2019, 33(02):105-111.(In Chinese)

[6] Fehr E, Schmidt K M. A Theory of Fairness, Competition and Cooperation [J]. Quarterly Journal of Economics, 1999, 114(3): 817-868.

[7] Du S, Nie T, Chu C, et al. Newsvendor model for a dyadic supply chain with Nash bargaining fairness concerns [J]. International Journal of Production Research, 2014, 52(17):5070-5085. 